\title{
Aquaporins 1, 3 and 8 expression in irritable bowel syndrome rats' colon via NF-kB pathway
}

\author{
Guanqun Chao ${ }^{1}$ and Shuo Zhang ${ }^{2}$ \\ ${ }^{1}$ Department of Family Medicine, Sir Run Run Shaw Hospital, Zhejiang University, Hangzhou, China \\ ${ }^{2}$ Department of Gastroenterology, The First Affiliated Hospital, Zhejiang Chinese Medical University, Hangzhou, China \\ Correspondence to: Shuo Zhang, email: zhangshuotcm@163.com
}

Keywords: irritable bowel syndrome, aquaporins, NF- $K B$

Received: November 04, 2016

Accepted: April 18, 2017

Published: May 02, 2017

Copyright: Chao et al. This is an open-access article distributed under the terms of the Creative Commons Attribution License 3.0 (CC BY 3.0), which permits unrestricted use, distribution, and reproduction in any medium, provided the original author and source are credited.

\section{ABSTRACT}

Objective: Our research was to detect the expression of aquaporins. NF-KB in Irritable bowel syndrome (IBS) rat models' colon so as to find novel pathogenesisof IBS.

Results: The expression of AQP1, AQP3, and AQP8 of IBS model group was downregulated while NF-KB p65 was up-regulated comparing with control group $(p<0.05)$, and the expression of AQP1, AQP3, and AQP8 of inhibitor group was up-regulated while NF-KB p65 was down-regulated comparing with IBS model group $(p<0.05)$.

Materials and Methods: 18 adult female SD big rats were divided into three groups:the rats in control group were normal rats, the rats in IBS model group and the rats of inhibitor group were injected with the inhibitor of NF-KB (PDTC). Immunohistochemical technique and western blot were performed to detect the expression of AQP1, AQP3, AQP8 and NF-KB P65. RT-PCR was performed to detect the expression of AQP1, AQP3, and AQP8.

Conclusions: Liquid water metabolic abnormalities and intestine permeability alteration might be the mechanism of IBS by down-regulating AQP1, AQP3 and AQP8 via NF-kB pathway.

\section{INTRODUCTION}

Irritable bowel syndrome (IBS) is a common functional gastrointestinal disorder, appearing as complex symptoms such as abdominal pain/discomfort [1]. As a chronic biopsychological disorder, IBS is characterized by altered bowel habits excluding organic disorders. Except for the astrointestinal motility abnormality and distorted visceral perception of sensation, IBS is also connected with several gastrointestinal and extraintestinal manifestations [2]. Although IBS is one of the most common disease, the etiology of the disease remains unknown. Several physical and psychological factors, such as stress, anxiety, and abnormal attitudes towards illness, are known to contribute to IBS's pathogenesis [3]. Nowadays the worldwide prevalence of IBS ranges from $3 \%$ to $22 \%$ of the population [4] and in America, IBS affects 15\% of the population [5]. Current evidence figures out that the diagnosis of IBS is still according to Rome IV and the actual quantity of the presence of such underlying cause of IBS , however, IBS's pathogenesis remains unknown.
Therefore, the objective of our research was to find novel pathogenesis so as to contribute to the treatment of IBS.

In the human body, aquaporins (AQPs) are considered play important roles in the water transport system [6]. There are currently 13 types of $\mathrm{AQP}, \mathrm{AQP} 0$ through $\mathrm{AQP} 12$, which are expressed in various organs. Taking intestinal tract as example, AQP1, AQP3, AQP4, AQP7, AQP8, AQP9, and AQP10 has been found expressed in the colon, which affects fecal water content [7-9]. It has been improved that the functions of AQPs in the stomach and intestine physiology may involve water transfer, gastric juice secretion, barrier function, as well as absorption and secretion of water and even small solutes through the epithelium [7, 10]. As the gastrointestinal tract is the major organ for water transport which is only secondary to kidney, IBS might have some change in water transport through $\mathrm{AQP}$ s.It has been found that $\mathrm{AQP1}, \mathrm{AQP} 3, \mathrm{AQP} 8$ were abundantly expressed in rat intestinal epithelial cells, and were also expressed in the human colon, as a result of this, we chose to study these three AQPs [11-12].

The nuclear factor-kappa B (NF-B), which can be activated by a variety of stimuli such as virus infection, 
activation of kinases and oncogenes, overproduction of cytokines, and dysregulation of cell surface receptors, plays an important role in the process of immune responses and inflammation [13]. It has been reported that the expression of AQP5 mRNA in the parotid gland was down-regulated after LPS inducing, which is mediated via transcription factors NF-kB and p-c-Jun/c-Fos [14]. Another research reported that NF-kB activation is of great importance for the down-regulation of AQP2 channel and vasopressin receptor expression during sepsis [15].As a result of the mechanism of IBS include immune responses and inflammation, we speculated that NF-kB pathway might play an important role in IBS. Our research was to detect the expression of AQPs in IBS rat models and to detect the expression of AQPs with the inhibitor of NF-kB so as to elucidate the mechanism of IBS.

\section{RESULTS}

\section{The change of the model}

After completing the models, we found that there was no change of behavior. Rats of IBS model group (including model group and inhibitor group before injection) expressed excessive reaction when they were frightened or they were performed by intragastric administration. There was also no change of their stool.

\section{Model authentication}

The rectum effusion amount of the model rats(including model group and inhibitor group before injection) (0.88 \pm $0.16 \mathrm{ml})$ were lower than the control group $(1.42 \pm 0.11 \mathrm{ml})$, the difference had statistical signifcance $(P<0.01)$, which suggested that model building method was successful (Table 1).

\section{The expression of AQP1 in the colon by immunohistochemical technique}

\section{AQP1 cell immunochemical staining}

AQP1 positive reaction material presents brown, the cell membrane and cytoplasm were dyed, and the negative control was not dyed (Figure 1).
The expression of AQP1 comparing among the different group

The positive cell numbers of model group was less than the control group $(P<0.05)$, the positive cell numbers of inhibitor group was more than model group $(P<0.05)$, and the positive cell numbers of inhibitor group was more than control $\operatorname{group}(P<0.05)$ (Table 2).

\section{The expression of AQP3 in the colon by immunohistochemical technique}

\section{AQP3 cell immunochemical staining}

AQP3 positive reaction material presents brown, the cell membrane and cytoplasm were dyed, and the negative control was not dyed. (Figure 2).

\section{The expression of AQP3 comparing among the different group}

The positive cell numbers of model group was less than the control group $(P<0.05)$, and the positive cell numbers of inhibitor group was more than model group $(P<0.05)$, nevertheless, there was no significant divergence between control group and inhibitor group $(p>0.05)$ (Table 2).

\section{The expression of AQP8 in the colon by immunohistochemical technique}

\section{AQP8 cell immunochemical staining}

AQP8 positive reaction material presents brown, the cell membrane and cytoplasm were dyed, and the negative control was not dyed. (Figure 3)

\section{The expression of AQP8 comparing among the different group}

The positive cell numbers of model group was less than the control group $(P<0.05)$, the positive cell numbers of inhibitor group was more than model group $(P<0.05)$, and the positive cell numbers of inhibitor group was more than control group $(P<0.05)$. (Table 2$)$



Figure 1: The expression of AQP1 in the colon by immunohistochemical technique (*400) AQP1 positive reaction material presents brown, the cell membrane and cytoplasm were dyed. 
Table 1: The water injection rate when AWR score was 3

\begin{tabular}{|c|c|c|c|}
\hline & Control group (ml) & & l group $(\mathrm{ml})$ \\
\hline $\begin{array}{l}\text { The water } \\
\text { injection rate }\end{array}$ & $1.467 \pm 0.054$ & & \pm 0.143 \\
\hline \multicolumn{4}{|c|}{$P<0.05$ compare with control group. } \\
\hline & Control group & Model group & Inhibitor group \\
\hline AQP1 & $1.348 \pm 0.190$ & $0.3031 \pm 0.048^{a}$ & $0.675 \pm 0.077^{b}$ \\
\hline AQP3 & $2.011 \pm 0.178$ & $0.957 \pm 0.138^{a}$ & $1.859 \pm 0.176^{b}$ \\
\hline AQP8 & $2.401 \pm 0.216$ & $0.609 \pm 0.120^{a}$ & $1.847 \pm 0.190^{b}$ \\
\hline P65 & $0.204 \pm 0.022$ & $2.129 \pm 0.263^{a}$ & $0.425 \pm 0.054^{b}$ \\
\hline
\end{tabular}

${ }^{a} P<0.05$ compare with control group; ${ }^{b} P<0.05$ compared with model group.

\section{The expression of NF-kB p65 in the colon by} immunohistochemical technique

\section{NF-kB p65 cell immunochemical staining}

NF-kB p65 positive reaction material presents brown, the cell nucleus was dyed, the cell membrane and cytoplasm were not dyed, and the negative control was not dyed (Figure 4).

The expression of NF-kB p65 comparing among the different group

The positive cell numbers of model group was more than the control group $(P<0.05)$, and the positive cell numbers of inhibitor group was less than model group $(P<0.05)$, nevertheless, there was no significant divergence between control group and inhibitor group $(p>0.05)$ (Table 2).

The expressions of AQP1, AQP3, AQP8 in the colon by PCR technique

The expressions of AQP1, AQP3 and AQP8 mRNA of model group were less than the control group $(P<0.05)$, and the expressions of inhibitor group were more than model group $(P<0.05)$, however, there was no difference between control group and inhibitor group $(p>0.05)$ (Table 3).

The expressions of AQP1, AQP3, AQP8 and NFkB p65 in the colon by Western blot technique

The expressions of AQP1, AQP3 and AQP8 protein of model group were less than the control group $(P<0.05)$, and the expressions of inhibitor group were more than model group $(P<0.05)$, nevertheless, there was no significant divergence between control group and inhibitor group $(p>0.05)$. The expressions of NF-kB p65 protein of model group were more than the control group $(P<0.05)$, the expressions of inhibitor group were less than model group $(P<0.05)$, and the expression of inhibitor group was more than control group $(P<0.05)$. (Figure 5) (Table 4)

\section{DISCUSSION}

According to Rome IV criteria, the diagnostic criteria for Irritable bowel syndrome is defined as recurrent abdominal pain on average at least 1 day/week

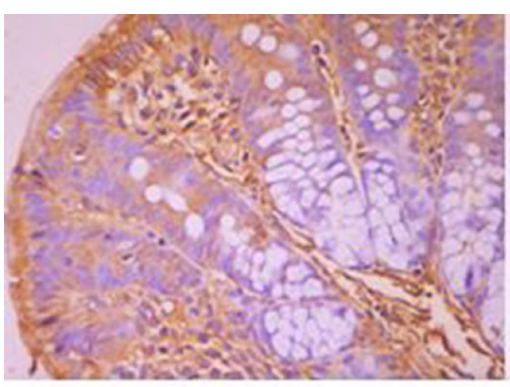

Control group

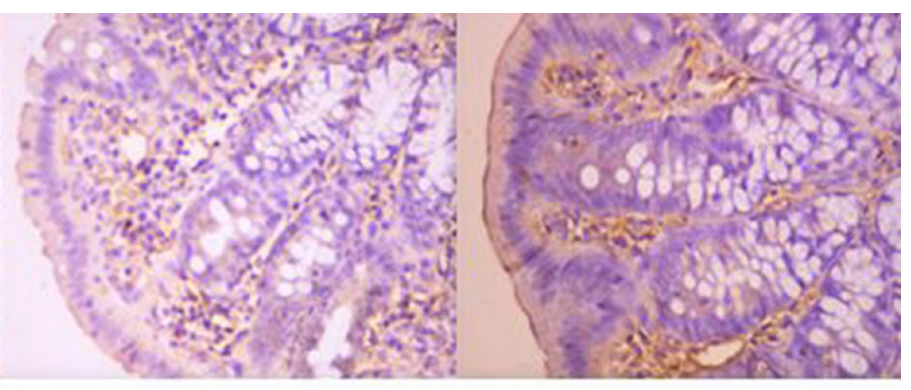

Model group

Inhibitor group

Figure 2: The expression of AQP3 in the colon by immunohistochemical technique (*400) AQP3 positive reaction material presents brown, the cell membrane and cytoplasm were dyed. 
Table 3: The expressions of AQP1, AQP3, AQP8 in the colon by RT-PCR technique

\begin{tabular}{llll}
\hline & Control group & Model group & Inhibitor group \\
\hline AQP1 & $27.720 \pm 0.841$ & $24.511 \pm 0.472^{a}$ & $26.776 \pm 0.695^{b}$ \\
AQP3 & $24.163 \pm 1.027$ & $20.814 \pm 0.569^{a}$ & $23.492 \pm 0.853^{b}$ \\
AQP8 & $27.387 \pm 0.850$ & $23.438 \pm 0.548^{a}$ & $26.007 \pm 0.781^{b}$ \\
\hline
\end{tabular}

${ }^{\mathrm{a}} P<0.05$ compare with control group; ${ }^{\mathrm{b}} P<0.05$ compared with model group.

in the last 3 months, associated with 2 or more of the following:related to defecation,associated with a change in frequency or form (appearance) of stool [16]. IBS is a chronic biopsychological disorder which has complex symptoms appearing as altered bowel habits without organic pathology[17]. As we know, IBS is so common that it affects nearly $10-20 \%$ of adolescents and adults in western societies and is also the frequentest cause of children with recurrent abdominal pain [18, 19]. Several hypotheses have been proposed that the pathogenesis of IBS includes altered gut microbiota, visceral hypersensitivity, dysmotility, gastrointestinal infection and infestation, dysregulation of brain-gut axis, psychological and genetic factors [20]. Despite the growing body of literature, IBS pathophysiology remains poorly understood.

Nowadays, at least 13 types of AQPs (AQP0-12) have been identified in mammals. AQP0, AQP1, AQP2,
AQP4, AQP5, AQP6 and AQP8 are reported be selectively permeable to water; and $\mathrm{AQP} 3, \mathrm{AQP} 7, \mathrm{AQP} 9, \mathrm{AQP} 10$ are permeable to water, glycerol and urea [21].In mammals, AQPs are widely present in the digestive tract, including salivary gland, esophagus, stomach, small and large intestines, liver, gallbladder, bile duct and pancreas[22]. Currently several researches reported that AQPs play important roles in gastrointestinal diseases, however, there is few research reported about IBS. It isreported that several AQP types are found in gastrointestinal epithelia, with AQP1, 3, 7, 10 and 11 being the most abundantly expressed in the whole digest tract, and AQP4 and 8 are expressed selectively in the stomach and colon [23]. Several studies revealed that AQP1, AQP3 and AQP8 are closely connected with water transportation in colon $[23,24]$. Another research showed that AQP-1 increases osmotic water permeability and locally facilitates the

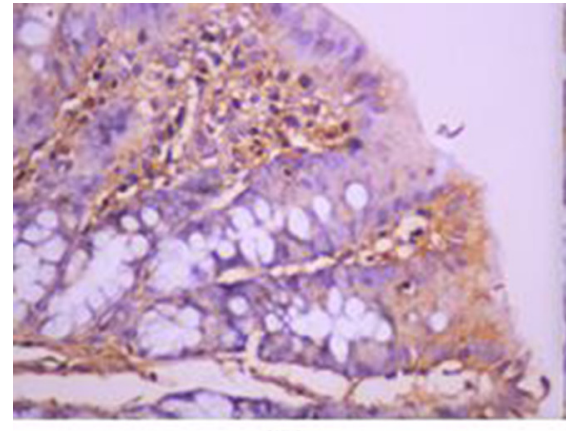

Control group

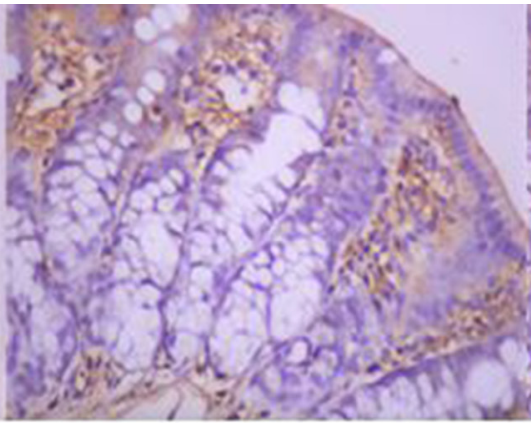

Model group

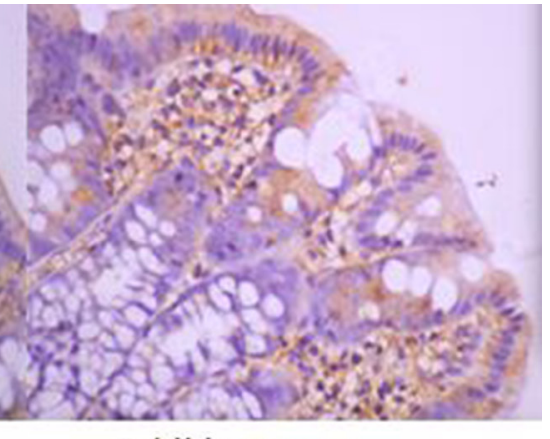

Inhibitor group

Figure 3: The expression of AQP8 in the colon by immunohistochemical technique (*400) AQP8 positive reaction material presents brown, the cell membrane and cytoplasm were dyed.

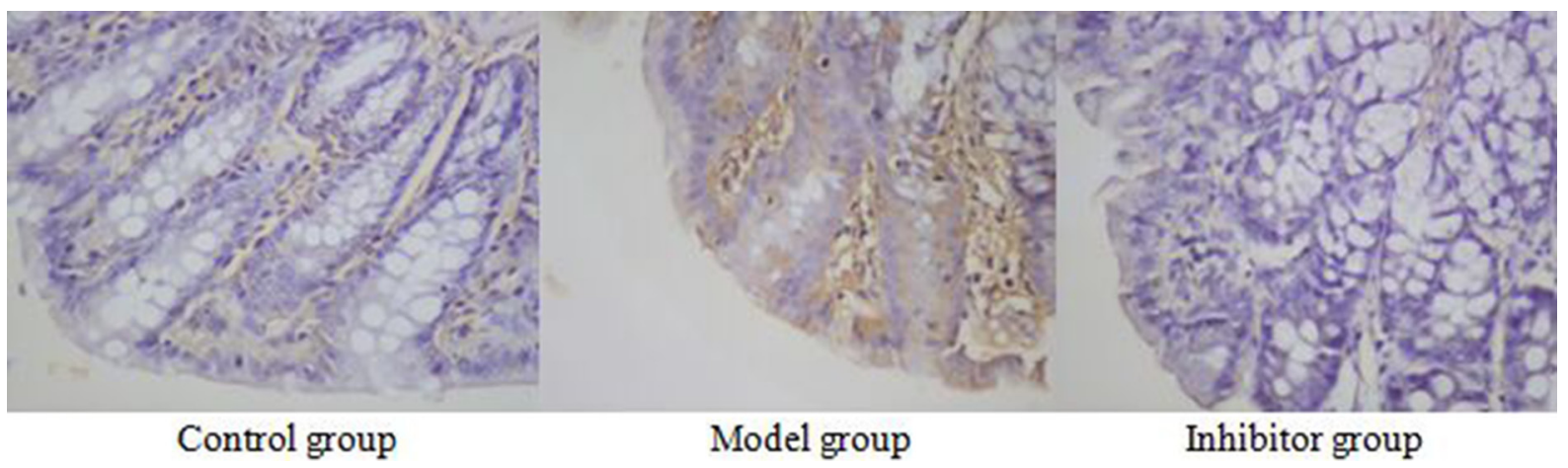

Figure 4: The expression of NF-KB p65 in the colon by immunohistochemical technique (*400) NF-kB p65 positive reaction material presents brown, the cell nucleus was dyed, the cell membrane and cytoplasm were not dyed. 
Table 4: The expressions of AQP1, AQP3, AQP8 and NF-kB p65 in the colon by Western bolt technique

\begin{tabular}{lccc}
\hline & Control group & Model group & Inhibitor group \\
\hline AQP1 & $29.325 \pm 0.305$ & $19.708 \pm 0.744^{a}$ & $27.310 \pm 0.985^{b}$ \\
AQP3 & $29.263 \pm 0.318$ & $19.557 \pm 0.944^{a}$ & $27.633 \pm 0.683^{b}$ \\
AQP8 & $28.647 \pm 0.355$ & $21.105 \pm 0.621^{a}$ & $27.885 \pm 1.716^{b}$ \\
P65 & $13.210 \pm 0.933$ & $56.818 \pm 2.834^{a}$ & $21.888 \pm 1.237^{b}$ \\
\hline
\end{tabular}

${ }^{\mathrm{a}} P<0.05$ compare with control group; ${ }^{\mathrm{b}} P<0.05$ compared with model group

rapid, trans-membrane flux of water in plasma membrane blebs [25]. It is also reported that in the mediation of AQP3,the fecal water content in the colon is controlled by the transport of water from the luminal side to the vascular side[26]. The knockdown of AQP3 was reported to be connected with a decreasing of the expression of Claudin-1 and Occludin and the increasing of bacteria translocation, which revealed that $\mathrm{AQP} 3$ was associated with intestinal permeability. In our research, we found that the expressions of AQP1, AQP3 and AQP8 of model group were down-regulated comparing with the control group which suggested that liquid water metabolic abnormalities might be one of the mechanisms of IBS connecting with AQPs. On the other hand, as the connection of AQPs and Occludin expression, it is also revealed that tight junction or intestine permeability might be another mechanism of IBS regulated by AQPs.

NF-kB protein family include RelA (p65), Rel (c-Rel), RelB, NF-kB1 (p50), and NF-kB2 (p52), composed by a conserved Rel homology domain which is responsible for dimerization, nuclear localization and DNA-binding [27]. NF-kB pathway can be activated through two distinct signaling pathways: the classical pathway and the alternative pathway, and in the classical pathway, degradation of IkBa by IKKb activation triggers the translocation of various heterodimers, predominantly $\mathrm{p} 65 / \mathrm{p} 50$, to the nucleus [28]. The heterodimer of NF$\kappa \mathrm{B}$ p65 and p50 subunit is a common form of NF-kB. $\mathrm{NF}-\mathrm{kB}$ was also reported as an important pathway in the chronic intestinal inflammation [29]. That periostin mediates intestinal inflammation via the activation of NF- $\kappa \mathrm{B}$ pathway, which suggests that periostin may be a potential therapeutic target for inflammatory bowel disease [30] has been reported. One latest study showed that the activation of TLR4 by NCI increase CBS expression, which is mediated by the NF- $\mathrm{BB}$ pathway, final lead to visceral hypersensitivity [31]. In our research, we found that NF- $\mathrm{KB}$ p65 of model group was up-regulated, and after the inhibitor of NF- $\mathrm{KB}$ pathway, the expression of NF- $\kappa B$ p65 was down-regulated again, which revealed NF- $\kappa B$ pathway played a role in the mechanism of IBS. And as NF-kB is a main regulator of inducing several genes including inflammatory and immune response, we suspected that the mechanism of NF- $\mathrm{KB}$ pathway for IBS might involve in the immune, inflammation and visceral hypersensitivity.

Until now we can't search the study about IBS connected with AQP and NF-KB pathway. There was a

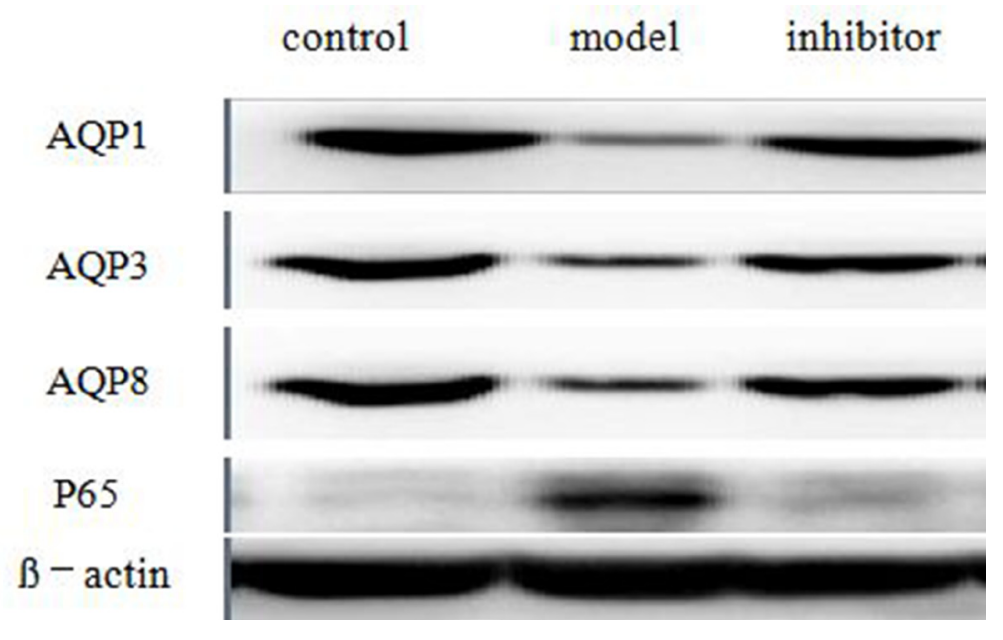

Figure 5: The expressions of AQP1, AQP3, AQP8 and NF-кB p65 in the colon by Western blot technique. The expressions of AQP1, AQP3 and AQP8 protein of model group were less than the control group $(p<0.05)$, and the expressions of inhibitor group were more than model group $(p<0.05)$, The expressions of NF-kB p65 protein of model group were more than the control group ( $p<0.05)$, and the expressions of inhibitor group were less than model group $(p<0.05)$. 
study found that once NF- $\mathrm{B}$ activated by a hypertonic medium, can decreased AQP-2 mRNA and protein expression through binding of NF- $\kappa \mathrm{B}$ complexes to specific $\mathrm{kB}$ elements of the AQP-2 promoter [32]. That IL-1 $\beta$ induces expression of AQP4 through a NF-kB pathway without involvement of denove protein synthesis in rat astrocytes has been reported [33]. Another study reported that lack of AQP5 showed declined activation of mitogenactivated protein kinase and NF- $\kappa \mathrm{B}$ pathways in lungs before and after Pseudomonas aeruginosa(PA) infection [34]. In our research, the expression of AQP1, AQP3 and AQP8 was up-regulated after the injection of inhibitor of $\mathrm{NF}-\kappa \mathrm{B}$ pathway. Thus, our research revealed that liquid water metabolic abnormalities and intestine permeability might be the mechanism of IBS by regulating AQP1, AQP3 and AQP8 via NF- $\mathrm{B}$ pathway. Worth attention, we found that the IBS model rats could not return to the normal state of the control group by inhibiting NF- $\kappa B$.

\section{MATERIALS AND METHODS}

\section{Subjects}

There were 18 adult female SD big rats, the weight of every rat was about $200 \mathrm{~g}$. Feeding environment was provided by experimental animal center of Zhejiang Chinese Medical University. 18 SD rats were divided randomly into three groups. The control group was 6 , model group was 6, and inhibitor group was 6 . They were put into the environment where the temperature was $22-24^{\circ} \mathrm{C}$, the humidity $<60 \%$, the noise $<50 \mathrm{db}$.

\section{Experimental procedure and methods}

\section{Group}

\section{Control group}

They were normal rats. The control group was injected by $1 \mathrm{ml}$ saline for control. After 2 weeks of normal eating and drinking, we observed the condition of rats. Then the rats' visceral sensitivity was evaluated by abdominal withdraw reaction. The AWR scoring criteria are shown in Table 5 [35].

\section{Model group}

The conditioned stimulus was camphor ball special odor. The unconditioned stimulus was rectal distention pressure $(>60 \mathrm{mmHg}(1 \mathrm{mmHg}=0.133 \mathrm{kPa}))$ combining with extremities constraint. Rats were put into the cage with camphor ball in it, we fixed the extremities and trunk of the rats for $45 \mathrm{~min}$. At this time inserted catheter into rectum. The distance from air ballon distal end to anal was about $1 \mathrm{~cm}$. The catheter was fixed at the root of the tail. The balloon volume was $1.6 \mathrm{ml}$ (hydrostatic pressure in Ballon's space $>60 \mathrm{mmHg}$ ) and lasted for $60 \mathrm{~s}$, intermittent exhaust 3 mins and filled gas 10 times once.
This was a stress process. There was one process in the first day, the same process was performed on the second day at the same time. The conditioned stimulus Without the unconditioned stimulus was done on the fourth day. The completed process was repeated once on the fifth day. The process same as the fourth day was performed on the sixth day. The conditioned stimulus was performed on the eighth day $[36,37]$. Then the rats' visceral sensitivity was evaluated by abdominal withdraw reaction.

\section{Inhibitor group}

The IBS model rats were injected into the abdominal cavity with the inhibitor of NF-kB (PDTC, $50 \mathrm{mg} / \mathrm{kg} / \mathrm{d}$ ) once after completing the models.

\section{Model authentication}

Visceral sensitivity was evaluated by abdominal withdraw reaction (AWR). $8 \mathrm{~F}$ urethral catheter which was lubricated by liquid paraffin was inserted per anum. The distance from air ballon distal end to anal was about $1 \mathrm{~cm}$, and it was fixed at the root of the tail. The rats were put on the platform, after they accommodated the environment, we gradually affused water into sacculus, and recorded the water injection rate when the rats raised the abdomen and made the back like a bow when AWR score was 3. Rectal distention lasted for $30 \mathrm{~s}$ every time, and repeated 3 times. And then we took the mean number.

\section{Experimental sample}

After a laparotomy incision, a portion of the colon was removed and placed in an oxygenated Tyrode's solution. A segment of $2 \mathrm{~cm}$ length colon were mounted in a $10 \mathrm{ml}$ organ bath containing Tyrode's solution that was bubbled with a $95 \% \mathrm{O} 2$ and 5\% CO2 mixture, and the temperature was held at $37^{\circ} \mathrm{C}$.

\section{Experimental procedure (immunohistochemical technique)}

\section{Two footwork}

We dropwised 3\% hydrogen dioxide on tissue away from light and incubated for $15 \mathrm{~min}$. And then the tissue was flushed by distilled water, and we put the chips into PBS balanced solution, and soaked for $5 \mathrm{~min}$, for 3 times. AG dark was repaired. We dropped 50-100 ml antibody fluid on the tissue, and incubated for $30 \mathrm{~min}$ in the ambient temperature. Then we washed chips with PBS, and soaked the chips in PBS balanced solution for 4 min 3 times. Then we dropped appreciable proportion diluted biotin labeling antibody (1\%BSA-PBS to dilute), and incubated for $30 \mathrm{~min}$ in the ambient temperature. After that we washed the chips with PBS, and soaked them in the PBS balanced solution for $5 \mathrm{~min} 3$ times. Then we dropped 50-100 ml 
Table 5: Abdominal withdrawal reflex (AWR) scoring criteria

\begin{tabular}{ll}
\hline Score $\mathbf{0}$ & No behavioral response to colorectal distension (CRD) \\
\hline Score 1 & $\begin{array}{l}\text { Immobile during distension of colorectum (CR) and occasional appearance of brief head motion after a } \\
\text { pause at the onset of the stimulation }\end{array}$ \\
Score 2 & $\begin{array}{l}\text { A mild contraction of abdominal muscles, but no lifting of abdomen off the plattorm } \\
\text { Score } 3\end{array}$ \\
$\begin{array}{l}\text { A strong contraction of abdominal muscles and lifting of abdomen off the platform, no lifting of pelvic } \\
\text { structure off the platform }\end{array}$ \\
Score 4 & Arching body and lifting of pelvic structure and scrotum \\
\hline
\end{tabular}

developer DAB fluid, and incubated for 5-20 min, after coloration completely, and then the tissue was washed by distilled water. The tissue was dewatered by $85 \%, 90 \%$, $95 \%, 100 \%, 100 \%, 100 \%$ alcohol. Then we put the chips into xylene for $5 \mathrm{~min}, 3$ times.

\section{Negative control}

Replaced one antibody with PBS, the consequence was negative.

\section{Analytical method}

We used the computer image analysis software (the Carl Zeiss of the Imaging Systems of the Carl Zeiss company) to analyze images. The images were put under 40 times object glass. We found the typical places, and took 10 high power campus visualis $(\times 400)$ successively. Then we analyzed the masculine expression by quantitative analysis and calculated photodensity.

\section{Experimental procedure (RT-PCR technique)}

Total RNA was extracted from duodenal tissues with Trizol (Invitrogen, Gaithersburg, MD, USA) using the one-step method. After purification, RNA concentration was analyzed using Nanodrop (Nanodrop Technologies, Wilmington, DE) and quality testing was conducted using BioAnalyzer (Agilent Technologies, Palo Alto, CA). After preparing total RNA, we did primer test and sample assay. Then we performed reverse transcription. After creating and setting up a plate document, we prepared the PCR reaction plate, after that we run the PCR reaction plate, then we analyzed the result. he main procedure was high-throughput sequencing on independent samples. Small RNA was purified from total RNA to enrich molecules in the range of 16-30 nt, and then $3^{\prime}$ and $5^{\prime}$ linker sequences were attached, and SuperScript II reverse transcriptase was used to synthesize cDNA. PCR amplification was conducted.

\section{Experimental procedure (Western blot technique)}

Protein measurements were performed on the prepared cell extracts and 7.5\% SDS gel was also prepared.
After the polymerization of the gel, the cell extracts were diluted in the sample buffer and boiled at $95^{\circ} \mathrm{C}$ for $5 \mathrm{~min}$. With the samples executed in the gel, proteins were transferred into membranes by the use of semidry transfer method. The transfer will be realized at $100 \mathrm{~V}$ within $1 \mathrm{~h}$. It was held in PBS solution (blocking solution) with 5\% milk powder and $0.1 \%$ tween 20 . The membrane will be incubated with primer antibodies overnight. And the membrane was washed 3 times using PBS solution with $0.1 \%$ Tween 20 for $5 \mathrm{~min}$ and second antibody application was performed. After membrane incubation with rabbit second antibody for $1 \mathrm{~h}$, it was again washed 3 times using PBS solution with $0.1 \%$ Tween 20 for 5 min. ECL solution was used with the purpose of viewing and filming proteins in the membrane. Horseradish peroxidase enzyme linked to the second antibody catalyzes Lumigan PS-3 substrate in ECL solution.

\section{Statistical analysis}

The data was demonstrated as $x \pm$ SE. We used SPSS 17.0 software as statistical method.evene's test for equality of variances, differences between three groups were compared using one-factor analysis of variance (ANOVA), tatistical significance was taken as $P<0.05$.

\section{CONCLUSIONS}

As a chronic biopsychological disorder, IBS is characterized by altered bowel habits excluding organic disorders.However, the real mechanism of IBS remains unknown. Our research showed that liquid water metabolic abnormalities and intestine permeability Alteration might be the mechanism of IBS by down-regulating AQP1, AQP3 and AQP8 via NF-kB pathway.

\section{Authors' contributions}

Guanqun Chao did the research and wrote the article. Shuo Zhang guided the experiment.

\section{ACKNOWLEDGMENTS}

This work was partially supported by the Fund of Medicine and health science and technology plan projects 
in Zhejiang province (2017179719); Traditional Chinese medicine science and technology plan of Zhejiang province (2017ZA089); Traditional Chinese medicine science and technology plan projects of Zhejiang province (2016ZB071); and National Natural Science Foundation of China (81573760); and Traditional Chinese medicine science and technology plan projects of Zhejiang province (2015ZZ012); and medical health platform plan projects of Zhejiang province (2015RCA020); Zhejiang Provincial Natural Science Foundation of China (LY16H030010).

\section{CONFLICTS OF INTEREST}

None.

\section{REFERENCES}

1. Jarrett ME, Han CJ, Cain KC, Burr RL, Shulman RJ, Barney PG, Naliboff BD, Zia J, Heitkemper MM. Relationships of abdominal pain, reports to visceral and temperature pain sensitivity, conditioned pain modulation, and heart rate variability in irritable bowel syndrome. Neurogastroenterol Motil. 2016; 28:1094-103.

2. Drossman DA, Camilleri M, Mayer EA, Whitehead WE. AGA technical review on irritable bowel syndrome. Gastroenterology. 2002; 123:2108-31.

3. Naeem SS, Siddiqui EU, Kazi AN, Memon AA, Khan ST, Ahmed B. Prevalence and factors associated with irritable bowel syndrome among medical students of Karachi, Pakistan: a cross-sectional study. BMC Res Notes. 2012; 5:255.

4. Basandra S, Bajaj D. Epidemiology of Dyspepsia and Irritable Bowel Syndrome (IBS) in Medical Students of Northern India. J Clin Diagn Res. 2014; 8:JC13-6.

5. Fallah M, Pourrasouli Z, Ghasemipour R, Heidarzadeh A, Joukar F, Hammami P, Arami M, Keyhanian S, Keyhanian M, Masoudnia N, Ziaratban R. Irritable bowel syndrome (IBS) prevalence in medical students of Gilan University of Medical Sciences. Govaresh. 2006; 11:7-11.

6. Loo DD, Wright EM, Zeuthen T. Water pumps. J Physiol. 2002; 542:53-60.

7. Matsuzaki T, Tajika Y, Ablimit A, Aoki T, Hagiwara H, Takata K. Aquaporins in the digestive system. Med Electron Microsc. 2004; 37:71-80.

8. Mobasheri A, Wray S, Marples D. Distribution of AQP2 and AQP3 water channels in human tissue microarrays. J Mol Histol. 2005; 36:1-14.

9. Wang JP, Hou XH. Expression of aquaporin 8 in colonic epithelium with diarrhoea-predominant irritable bowel syndrome. Chin Med J (Engl). 2007; 120:313-6.

10. Laforenza U. Water channel proteins in the gastrointestinal tract. Mol Aspects Med. 2012; 33:642-50.

11. Matsuzaki T, Tajika Y, Ablimit A, Aoki T, Hagiwara H, Takata K. Aquaporins in the digestive system. Medical Molecular Morphology. 2004; 37:71-80.
12. Yde J, Keely S, Wu Q, Borg JF, Lajczak N, O'Dwyer A, Dalsgaard P, Fenton RA, Moeller HB. Characterization of AQPs in Mouse, Rat, and Human Colon and Their Selective Regulation by Bile Acids.Frontiers in Nutrition. 2016; 31-20.

13. DiDonato JA, Mercurio F, Karin M. NF- $\kappa B$ and the link between inflammation and cancer. Immunol Rev. 2012; 246:379-400.

14. Yao C, Purwanti N, Karabasil MR, Azlina A, Javkhlan P, Hasegawa T, Akamatsu T, Hosoi T, Ozawa K, Hosoi K. Potential down-regulation of salivary gland AQP5 by LPS via cross-coupling of NF-kappaB and p-c-Jun/c-Fos. Am J Pathol. 2010; 177:724-34.

15. Höcherl K, Schmidt C, Kurt B, Bucher M. Inhibition of NF-kappaB ameliorates sepsis-induced downregulation of aquaporin-2/V2 receptor expression and acute renal failure in vivo. Am J Physiol Renal Physiol. 2010;298:F196-204.

16. Schmulson MJ, Drossman DA.What Is New in Rome IV. J Neurogastroenterol Motil. 2017; 23:151-63.

17. Qureshi SR, Abdelaal AM, Janjua ZA, Alasmari HA, Obad AS, Alamodi A, Shareef MA. Irritable Bowel Syndrome: A Global Challenge Among Medical Students. Cureus. 2016; 8:e721.

18. Ringel Y, Drossman DA. Irritable bowel syndrome: classification and conceptualization. J Clin Gastroenterol. 2002; 35:S7-10.

19. El-Matary W, Spray C, Sandhu B. Irritable bowel syndrome: the commonest cause of recurrent abdominal pain in children. Eur J Pediatr. 2004; 163:584-8.

20. Ghoshal UC, Shukla R, Ghoshal U, Gwee KA, Ng SC, Quigley EM. The gut microbiota and irritable bowel syndrome: friend or foe? Int J Inflam. 2012; 2012:151085.

21. Zhu C, Chen Z, Jiang Z. Expression, Distribution and Role of Aquaporin Water Channels in Human and Animal Stomach and Intestines. Int J Mol Sci. 2016; 17.

22. Matsuzaki T, Tajika Y, Ablimit A, Aoki T, Hagiwara H, Takata K. Aquaporins in the digestive system. Med Electron Microsc. 2004; 37:71-80.

23. Laforenza U. Water channel proteins in the gastrointestinal tract. Mol Aspects Med. 2012; 33:642-50.

24. Zhao GX, Dong PP, Peng R, Li J, Zhang DY, Wang JY, Shen XZ, Dong L, Sun JY. Expression, localization and possible functions of aquaporins 3 and 8 in rat digestive system. Biotech Histochem. 2016; 91:269-76.

25. Huebert RC, Vasdev MM, Shergill U, Das A, Huang BQ, Charlton MR, LaRusso NF, Shah VH. Aquaporin-1 facilitates angiogenic invasion in the pathological neovasculature that accompanies cirrhosis. Hepatology. 2010; 52:238-48.

26. Ikarashi $\mathrm{N}$, Kon $\mathrm{R}$, Iizasa $\mathrm{T}$, Suzuki N, Hiruma $\mathrm{R}$, Suenaga K, Toda T, Ishii M, Hoshino M, Ochiai W, Sugiyama K. Inhibition of aquaporin-3 water channel in the colon induces diarrhea. Biol Pharm Bull. 2012; 35:957-62.

27. Prasad S, Ravindran J, Aggarwal BB. NF-kappaB and cancer: how intimate is this relationship. Mol Cell Biochem. $2010 ; 336: 25-37$. 
28. Maruyama W, Shirakawa K, Matsui H, Matsumoto T, Yamazaki H, Sarca AD, Kazuma Y, Kobayashi M, Shindo K, Takaori-Kondo A. Classical NF- $\mathrm{B}$ pathway is responsible for APOBEC3B expression in cancer cells. Biochem Biophys Res Commun. 2016; 478:1466-71.

29. Vlantis K, Wullaert A, Polykratis A, Kondylis V, Dannappel M, Schwarzer R, Welz P, Corona T, Walczak H, Weih F, Klein U, Kelliher M, Pasparakis M. NEMO Prevents RIP Kinase 1-Mediated Epithelial Cell Death and Chronic Intestinal Inflammation by NF- $\mathrm{BB}-$ Dependent and -Independent Functions. Immunity. 2016; 44:553-67.

30. Koh SJ, Choi Y, Kim BG, Lee KL, Kim DW, Kim JH, Kim JW, Kim JS. Matricellular Protein Periostin Mediates Intestinal Inflammation through the Activation of Nuclear Factor $\kappa B$ Signaling. PLoS One. 2016; 11:e0149652.

31. Yuan B, Tang WH, Lu LJ, Zhou Y, Zhu HY, Zhou YL, Zhang $\mathrm{HH}, \mathrm{Hu} \mathrm{CY}, \mathrm{Xu}$ GY. TLR4 upregulates CBS expression through $\mathrm{NF}-\mathrm{\kappa B}$ activation in a rat model of irritable bowel syndrome with chronic visceral hypersensitivity. World J Gastroenterol. 2015; 21:8615-28.

32. Hasler U, Leroy V, Jeon US, Bouley R, Dimitrov M, Kim JA, Brown D,Kwon HM,Martin PY, Feraille E. NF- $\kappa B$ modulates aquaporin-2 transcription in renal collecting duct principal cells. J Biol Chem. 2008; 283:28095-105.
33. Ito H, Yamamoto $\mathrm{N}$, Arima H, Hirate H, Morishima $\mathrm{T}$, Umenishi F, Tada T, Asai K, Katsuya H, Sobue K. Interleukin-1beta induces the expression of aquaporin-4 through a nuclear factor-kappaB pathway in rat astrocytes. J Neurochem. 2006; 99:107-18.

34. Zhang ZQ, Song YL, Chen ZH, Shen Y, Bai CX. Deletion of aquaporin 5 aggravates acute lung injury induced by Pseudomonas aeruginosa. J Trauma. 2011; 71:1305-11.

35. Zhao JM, Chen L, Zhou CL, Shi Y, Li YW, Shang HX, $\mathrm{Wu} \mathrm{LY}$, Bao CH, Dou CZ, Wu HG.Comparison of Electroacupuncture and Moxibustion for Relieving Visceral Hypersensitivity in Rats with Constipation-Predominant Irritable Bowel Syndrome.Evid Based Complement Alternat Med. 2016; 2016:9410505.

36. Wang WA, Quan JM, Pan GZ. Development of irritable bowel syndrome animal model induced by brain gut interaction directed conditioned stress. Chinese Journal of Digestion. 2004; 24:592-3.

37. Naliboff BD, Chang L, Munakata J, Mayer EA. Towards an integrative model of irritable bowel syndrome. Prog Brain Res. 2000; 122:413-23. 